\title{
Comparability of "Enoxamed" a Tunisian Generic Enoxaparin with the Originator Product: Non-clinical and Clinical Studies
} \author{
my ${ }^{13}$, Wahid Bouida $\mathbf{M}^{2}$ and Semir Nouira ${ }^{2}$ \\ ${ }^{1}$ Biological Laboratory, Maternity and Neonatal Medicine Center, Monastir 5000, Tunisia \\ ${ }^{2}$ Emergency Department, Fattouma Bourguiba University Hospital, Monasitr 5000, Tunisia \\ ${ }^{3}$ Cardiology Department, Military University Hospital, Tunis, Tunisia \\ ${ }^{4}$ Cardiology Department, Habib Thameur University Hospital, Tunis, Tunisia \\ ${ }^{5}$ Cardiology Department, Hédi Chaker University Hospital, Sfax, Tunisia \\ ${ }^{6}$ Cardiology Department, Fattouma Bourguiba University Hospital, Monasitr 5000, Tunisia. \\ ${ }^{7}$ Cardiology Department, Farhat Hached University Hospital, Sousse 4000, Tunisia \\ ${ }^{8}$ Hematology Department, Fattouma Bourguiba University Hospital, Monastir 5000, Tunisia \\ ${ }^{9}$ Emergency Department, Farhat Hached University Hospital, Sousse 4000, Tunisia \\ ${ }^{10} \mathrm{Hematology}$ Department, Military University Hospital, Tunis, Tunisia \\ ${ }^{11}$ Hematology Department, Habib Thamer University Hospital, Tunis, Tunisia \\ ${ }^{12}$ Hematology Department, Farhat Hached University Hospital, Sousse 4000, Tunisia \\ ${ }^{13}$ Hematology Laboratory, Tenon Hospital, 75020 Paris, France
}

Mouna Sassi ${ }^{1 *}$, Kaouther Beltaief ${ }^{2}$, Habib Haouala ${ }^{3}$, Sondes Kraiem4, Samir Kammoun ${ }^{5}$, Faouzi Maatoug ${ }^{6}$, Gouider Jeridi ${ }^{7}$, Mohsen Hassine $^{8}$, Mahdi Methammem ${ }^{9}$, Ibrahim Nciri ${ }^{10}$, Sofiane Kammoun ${ }^{4}$, Mohamed Zili11, Mondher Kortas ${ }^{12}$, Mohamed Habib Grissa ${ }^{2}$, Ismail Elala-

\begin{abstract}
Enoxaparin is a complex, biologically derived low-molecular-weight heparin. The manufacturing process for biologics is complex which makes difficult to obtain exact replicas of the reference biologic. This is why there is a critical need to ensure that generics of biologic medicines are safe and effective. This study was carried out to assess the comparability of a Tunisian generic enoxaparin (Enoxamed ${ }^{\circledR}$, Unimed Laboratory, Tunisia) with the originator product (Lovenox ${ }^{\circledast}$; Sanofi US, Bridgewater, New Jersey) through non-clinical in vitro study in healthy volunteers and clinical studies (phases III and IV) in patients with acute coronary syndrome (ACS). For non-clinical study, blood from healthy volunteers was used to compare the effect of both formulations using anti-Xa activity and the thrombin generation test (TGT). All parameters of TGT were analyzed. For clinical studies, ACS patients were randomly assigned to receive Enoxamed ${ }^{\circledR}$ (27 in phase III and 120 in phase IV) or Lovenox ${ }^{\circledR}$ (23 in phase III and 118 in phase IV) and anti-Xa activity was measured $4 \mathrm{~h}$ thereafter. In healthy volunteers, the two products inhibited thrombin generation in a concentration-dependent manner. According to the profiles obtained from the TGT, Enoxamed ${ }^{\circledR}$ had similar potency as Lovenox ${ }^{\circledR}$. In ACS patients, anti-Xa activity was found no difference between Enoxamed ${ }^{\circledR}$ and Lovenox ${ }^{\circledast}$. No difference in major cardiovascular events was observed at 30 days after initial admission. Our finding combining anti-Xa activity and thrombin generation parameters would support the possibility to translate this biological efficacy to the clinical setting. The generic enoxaparin Enoxamed ${ }^{\circledR}$ showed comparability and then the main regulatory criteria of bioequivalence with the originator product.
\end{abstract}

Keywords: Enoxaparin; Generic; Anti-Xa activity; Thrombin generation test

\section{Introduction}

Enoxaparin, a complex, biologically derived low-molecular-weight heparin (LMWHs), is approved for a range of clinical indications. It is indicated for the prophylaxis and treatment of thrombotic events across a diverse set of disease states [1]. Studies comparing enoxaparin with unfractionated heparins (UFH) have revealed that enoxaparin has the following characteristics: an inexpressive effect on the risk of bleeding; a longer half-life; a longer-lasting therapeutic effect and no laboratory monitoring need [2]. Otherwise, enoxaparin experienced generic competition starting in 2010 [3]. In fact, generic versions of enoxaparin are available for clinical use in several countries $[4,5]$. However, the manufacturing process for biologics is complex which makes difficult to obtain exact replicas of the reference biologic. This is why there is a critical need to ensure that generics of biologic medicines are safe and effective. The complex structure and polypharmacological actions of LMWHs make producing copies more challenging than copies of small molecule medicine. Hence, the introduction of those enoxaparin generics has raised the debate about their similarities or comparability with the original drug [6,7]. The US Food and Drug Administration (FDA) and the European Medicines Agency (EMEA) developed guidelines for the acceptance of complex biological drugs including LMWHs. The FDA suggests an approach that integrates multiple measures to develop "fingerprints" that can be used to characterize complex products. However, The EMEA recommends that LMWHs should be compared not only by determining anticoagulant activities, such as anti-FXa and anti-FIIa but also by using other pharmacodynamic tests $[7,8]$. Interestingly, thrombin generation test (TGT) measures the ability of a plasma sample to generate thrombin following in vitro activation of coagulation with tissue factor or another trigger. It probes pro- and anticoagulant pathways and may be useful as indicator of overall plasma coagulability [9]. Otherwise, TGT is well

*Corresponding author: Mouna Sassi, Biological Laboratory, Maternity and Neonatal Medicine Center, University of Monastir, Tunisia, Tel: 0021698457304 Fax: 0021673908755; E-mail: mouna.bahrini@yahoo.fr

Received September 06, 2016; Accepted September 16, 2016; Published September 23, 2016

Citation: Sassi M, Beltaief K, Haouala H, Kraiem S, Kammoun S, et al. (2016) Comparability of "Enoxamed" a Tunisian Generic Enoxaparin with the Originator Product: Non-clinical and Clinical Studies. J Bioequiv Availab 8: 249-253. doi: 10.4172/jbb.1000304

Copyright: ( 2016 Sassi M, et al. This is an open-access article distributed under the terms of the Creative Commons Attribution License, which permits unrestricted use, distribution, and reproduction in any medium, provided the original author and source are credited. 
Citation: Sassi M, Beltaief K, Haouala H, Kraiem S, Kammoun S, et al. (2016) Comparability of "Enoxamed" a Tunisian Generic Enoxaparin with the Originator Product: Non-clinical and Clinical Studies. J Bioequiv Availab 8: 249-253. doi: 10.4172/jbb.1000304

documented to be a suitable tool for the monitoring of antithrombotic such as LMWHs [10]. It was already proposed as a suitable additional method for comparing the antithrombotic effects of enoxaparin copies $[1,10]$.

This study was carried out to assess the comparability of a Tunisian generic enoxaparin (Enoxamed', Unimed Laboratory, Tunisia) with the originator product (Lovenox; Sanofi US, Bridgewater, New Jersey) through non-clinical in vitro study in healthy volunteers using anti-Xa activity and TGT, and clinical studies (phases III and IV) in patients with acute coronary syndrome (ACS).

\section{Materials and Methods}

This study combined non-clinical in vitro trial conducted in healthy volunteers and clinical trials (phases III and IV) conducted in patients with ACS.

\section{The non-clinical in vitro study}

Blood collection and preparation: It was conducted in 10 age and sex-matched healthy volunteers not taking any medication interfering with hemostasis during the last 10 days. Blood was collected at fasting (8:00 AM) with atraumatic antecubital venipuncture into siliconized vacutainer tubes (Becton Dickinson, Meylan, France) containing buffered trisodium citrate $(0.129 \mathrm{~mol} / \mathrm{L}, 9$ parts of blood to 1 part of citrate solution). Poor platelet plasma (PPP) was obtained after a double centrifugation $\left(2500 \mathrm{xg}, 15 \mathrm{~min}, 22^{\circ} \mathrm{C}\right)$ of the citrated whole blood. The product Enoxamed and the originator product were mixed in vitro with the prepared PPP at different concentrations to reach a final concentration ranging from 0 to $10 \mathrm{ug} / \mathrm{mL}(0 \mathrm{ug} / \mathrm{mL} ; 2 \mathrm{ug} / \mathrm{mL} ; 4$ $\mathrm{ug} / \mathrm{mL} ; 6 \mathrm{ug} / \mathrm{mL} ; 8 \mathrm{ug} / \mathrm{mL}$ and $10 \mathrm{ug} / \mathrm{mL}$ ).

Pharmacological quantitative method: anti-Xa assessment: Anti-Xa activity of the different concentrations of each product was measured on STA COMPACT analyzer (Diagnostica Stago, Asnières, France). Anti-Xa activity was assessed using the STA Rotachrom Heparin reagent (Diagnostica Stago, Asnières, France).

Functional qualitative method: thrombin generation test: Thrombin generation was studied in vitro according to Hemker et al. [11] using the Calibrated Automated Thrombogram (CAT) assay (Thombinoscope b.v., Maastricht, The Netherlands) according to the manufacturer's instructions. Briefly, $80 \mu \mathrm{L}$ of each studied PPP, spiked with increasing concentrations of Enoxamed and the originator product, were mixed with $20 \mu \mathrm{L}$ of PPP reagent (Biodis, Stago) containing $5 \mathrm{pM}$ tissue factor and $4 \mu \mathrm{M}$ phospholipids (final concentrations) in 96-well microtiter plates. $20 \mu \mathrm{L}$ of fluorogenic substrate was added and then the fluorescence intensity was detected at a wavelength of $355 \mathrm{~nm}$ (excitation filter) and $460 \mathrm{~nm}$ (emission filter). The Thrombogram parameters analyzed were: (i) The lag-time of thrombin generation (lagtime); (ii) The time needed to reach the maximum concentration of thrombin (ttPeak); (iii) The maximum concentration of thrombin (Peak); and (iv) The mean rate index (MRI) of the propagation phase of thrombin generation calculated by the formula: Peak/(ttPeak-lagtime) and the area under the curve or endogenous thrombin potential (ETP) representing the total thrombin activity.

\section{The clinical studies}

\section{Phase III study}

Study design: It was a prospective, randomized-sequence, and monocentric study conducted at the emergency department of Fattouma Bourguiba University Hospital, Tunisia. It was performed in accordance with the revised declaration of Helsinki for Biomedical Research involving human subjects and the Guidelines for Good
Clinical Practice. The protocol was approved by the ethics committee of our institution. This trial was carried out between May and august 2013. Included patients were older than 18 years and fulfilled the criteria of ACS within $48 \mathrm{~h}$ of chest pain onset: signs suggestive of ACS without ST-segment elevation myocardial infarction, and electrocardiographic changes compatible with ischemia or elevated levels of cardiac biomarkers. Major exclusion criteria were: persistent ST-segment elevation, coagulation disorders, the use of any anticoagulant within the previous 3 months, pregnant or nursing woman, patient participating in another study, allergy to heparin, clinically significant hepatic disease, and end-stage renal disease requiring dialysis or a history of pathologic intracranial findings. Patients were randomized according to a report of $1 / 1$ using a table-generated randomization schedule. All included patients provided written informed consent. Baseline demographics with clinical history data were collected on a standardized data collection form. Eligible patients were assigned to the originator product or Enoxamed at the dose of $100 \mathrm{IU} / 1 \mathrm{~kg}$ subcutaneously. A clinical follow-up was conducted for all the included patients until 30 days ( \pm 5 days) after injection (complete physical examination and electrocardiogram).

The judging criteria: The main criterion was biological, the anti$\mathrm{Xa}$ activity. Sampling was performed at inclusion (H0) and $4 \mathrm{~h}$ after the first dose of the LMWHs (H4). The protocol of collection and preparation of blood was identical to that used in healthy volunteers. The PPP was aliquoted and stored at $-80^{\circ} \mathrm{C}$ until analysis.

The secondary criteria of judgment were clinical, the death and the occurrence of major adverse cardiovascular events (MACE).

\section{Phase IV study}

Study design and judging criteria: It was a prospective, open blinded end-point, randomized-sequence, and multicentric study conducted at the cardiology department of 5 Tunisian University Hospitals (Military Hospital-Tunis, Habib Thamer Hospital-Tunis, Fattouma Bourguiba Hospital-Monastir, Farhat Hached HospitalSousse and Hedi Chaker Hospital-Sfax). This trial was carried out between August and December 2015. Eligible patients were assigned to receive the originator product or Enoxamed at the dose of $100 \mathrm{IU} / 1$ $\mathrm{kg}$ subcutaneously. The study design and the judging criteria were the same as those adopted in the phase III study

\section{Statistics}

Data were presented as mean \pm standard deviation (SD) or median (25\% interquartile range) as appropriate. To compare the two groups (Originator and Enoxamed ${ }^{\circ}$ ), Student $t$ test was used for continuous variables and $\chi^{2}$ test for comparison of categorical variables. $P$ values $<0.05$ were considered statistically significant. Statistical analysis was performed with SPSS software version 20.0 (Chicago, IL, USA).

\section{Results}

\section{The non-clinical in vitro study}

The results of the anti-Xa activity carried out in healthy volunteers were shown in the Table 1. Enoxamed, similarly to the originator product, when added at increasing gravimetrically equivalent concentrations in normal PPP, induced a concentration-dependent increase of the anti-Xa activity in plasma. There were no significant statistical differences between the two products with regard to the anti$\mathrm{Xa}$ activity. The variability of the anti-Xa activity in normal PPP spiked with increasing concentrations of Enoxamed ${ }^{\circ}$ was about $2.7 \%$ and was similar to the interassay variability with the originator enoxaparin with a coefficient of variation of about $2.4 \%$. 
Citation: Sassi M, Beltaief K, Haouala H, Kraiem S, Kammoun S, et al. (2016) Comparability of "Enoxamed" a Tunisian Generic Enoxaparin with the Originator Product: Non-clinical and Clinical Studies. J Bioequiv Availab 8: 249-253. doi: 10.4172/jbb.1000304

When thrombin generation was assessed in normal PPP, chronometric parameters (lag-time and ttPeak) were elongated and the Peak, ETP and MRI were reduced in the presence of both Enoxamed and the originator enoxaparin. These two products inhibited thrombin generation in a concentration-dependent manner in normal PPP. As depicted in Figure 1, Enoxamed had similar potency as Lovenox.

\section{The clinical study}

Phase III study: A total of 50 patients with ACS were enrolled in the study, 27 received Enoxamed and 23 received Lovenox: Demographic characteristics and anti-Xa values (H0 and $\mathrm{H} 4$ ) were summarized in Table 2. There were no significant statistical differences between Enoxamed and Lovenox groups with regard to demographic characteristics. The mean enoxaparin dose was $7370 \pm 120 \mathrm{IU}$ in Enoxamed group as compared to $7782 \pm 290 \mathrm{IU}$ in Lovenox group (p $=0.18$ ). The anti-Xa activity was measured before administration of the anticoagulant in all patients. $4 \mathrm{~h}$ after administration of enoxaparin, the anti-Xa activity was $0.54 \pm 0.23 \mathrm{IU} / \mathrm{mL}$ for the Enoxamed group and $0.53 \pm 0.24 \mathrm{IU} / \mathrm{mL}$ for the Originator group. No significant difference was found between the two groups $(\mathrm{p}=0.82)$.
No deaths were noted in the 2 groups during follow-up until hospital discharge. In addition, no significant difference was observed between both groups with regard to MACE at 30 days after initial admission. There were no significant hemorrhagic complications in both groups during the follow-up.

Phase IV study: A total of 238 patients with ACS were enrolled in the 5 hospitals participating in this study, 120 received Enoxamed ${ }^{\circ}$ and 118 received Lovenox'. Demographic characteristics and anti-Xa values ( $\mathrm{H} 0$ and $\mathrm{H} 4$ ) were summarized in Table 3 . With regard to demographic characteristics, there were no significant statistical differences between Enoxamed and Lovenox groups The mean enoxaparin doses were

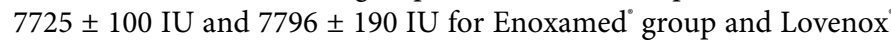
group respectively $(\mathrm{p}=0.17)$. The anti-Xa activity was $0.56 \pm 0.13 \mathrm{IU} / \mathrm{mL}$ for the Enoxamed group and $0.55 \pm 0.12 \mathrm{IU} / \mathrm{mL}$ for the Lovenox group. No significant difference was found between the two groups $(\mathrm{p}=0.71)$.

There were no significant hemorrhagic complications in both groups during the follow-up. No significant difference was observed between both groups with regard to death and MACE at 30 days after initial admission $(\mathrm{p}=0.31)$.

\begin{tabular}{|c|c|c|c|c|c|c|}
\hline & & $2 \mu \mathrm{g} / \mathrm{mL}$ & $4 \mu \mathrm{g} / \mathrm{mL}$ & $6 \mu \mathrm{g} / \mathrm{mL}$ & $8 \mu \mathrm{g} / \mathrm{mL}$ & $10 \mu \mathrm{g} / \mathrm{mL}$ \\
\hline \multirow{3}{*}{$\begin{array}{l}\text { anti-Xa Activity } \\
\text { (IU/mL) }\end{array}$} & Lovenox ${ }^{\circledR}$ & $0.19 \pm 0.015$ & $0.4 \pm 0.009$ & $0.61 \pm 0.008$ & $0.79 \pm 0.016$ & 0.99 \\
\hline & Enoxamed $^{\circledR}$ & $0.2 \pm 0.014$ & $0.38 \pm 0.01$ & 0.6 & $0.82 \pm 0.012$ & $0.99 \pm 0.009$ \\
\hline & $p$ & NS & NS & NS & NS & NS \\
\hline
\end{tabular}

NS: Not significant; values are mean \pm SD of 10 experiments

Table 1: Anti-Xa activities with Enoxamed ${ }^{\circledR}$ and Lovenox ${ }^{\circledR}$ in the non-clinical in vitro study.
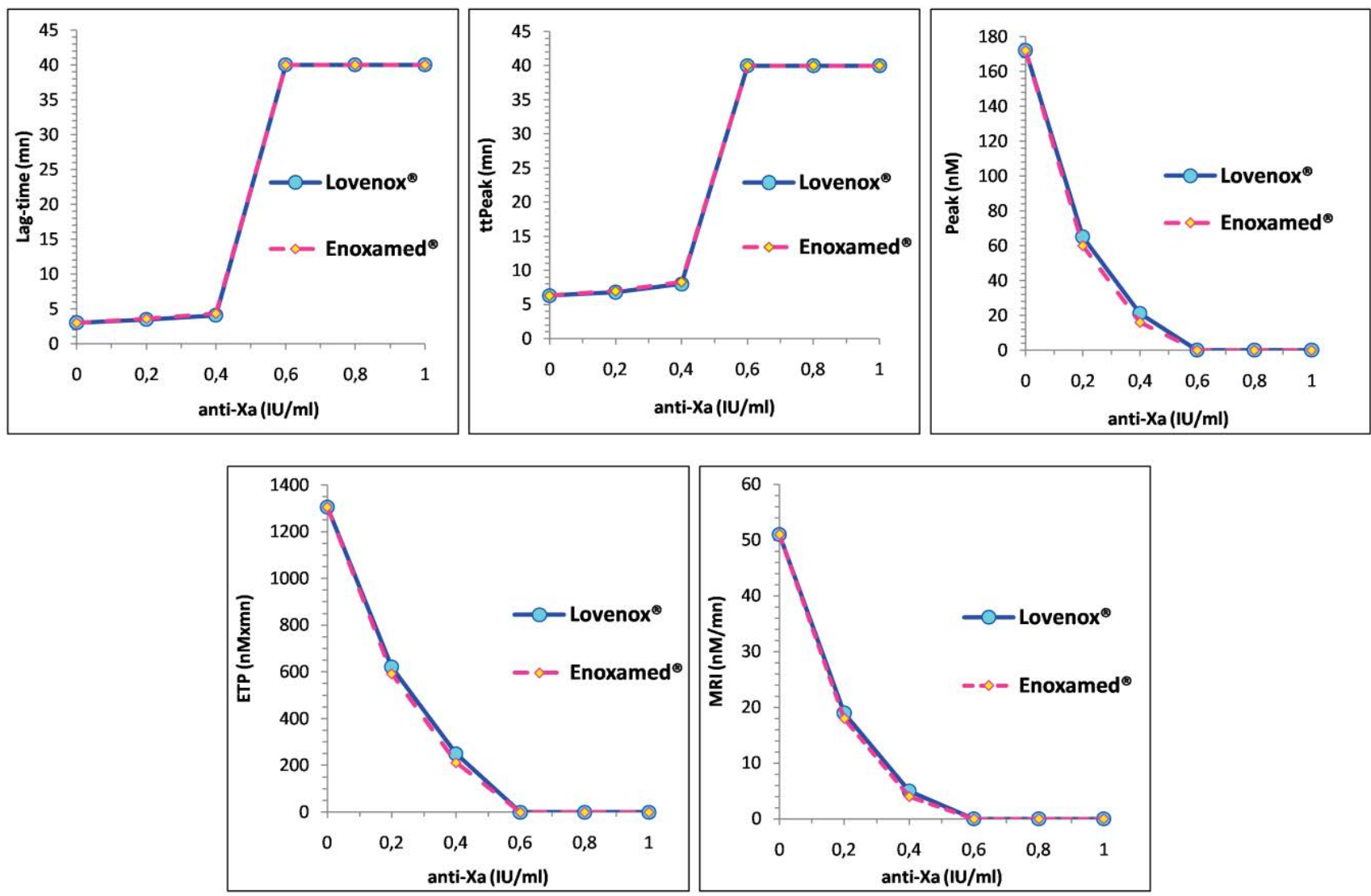

Figure 1: Effects of Enoxamed ${ }^{\circledR}$ and Lovenox ${ }^{\circledR}$ on thrombin generation parameters (lag-time, ttPeak; Peak, ETP, and MRI). 
Citation: Sassi M, Beltaief K, Haouala H, Kraiem S, Kammoun S, et al. (2016) Comparability of "Enoxamed" a Tunisian Generic Enoxaparin with the Originator Product: Non-clinical and Clinical Studies. J Bioequiv Availab 8: 249-253. doi: 10.4172/jbb.1000304

\begin{tabular}{|c|c|c|c|}
\hline \multirow{2}{*}{$\mathbf{n}$} & ENOXAMED & LOVENOX & \multirow{2}{*}{$\mathbf{2}$} \\
\cline { 2 - 3 } & $\mathbf{2 7}$ & $\mathbf{2 3}$ & \\
\hline \multicolumn{2}{|c|}{ Demographic characteristics } \\
\hline Age (year); mean \pm SD & $64.6 \pm 13$ & $62.7 \pm 9.7$ & 0.22 \\
\hline Sex ratio (M/F) & 2.4 & 1.3 & 0.31 \\
\hline Body mass index (kg/m²); mean \pm SD & $26.7 \pm 3.3$ & $28.4 \pm 4.6$ & 0.17 \\
\hline History of cardiovascular disease n (\%) & $17(70.8)$ & $10(47.6)$ & 0.11 \\
\hline Diabetes milletus n (\%) & $15(62.5)$ & $13(59.1)$ & 0.81 \\
\hline Heart failure $\mathrm{n}(\%)$ & $7(26.9)$ & $6(28.6)$ & 0.92 \\
\hline Biological assessment & & \\
\hline Anti-Xa activity (IU/mL), H0 & 0 & 0 & - \\
\hline Anti-Xa activity (IU/mL), H4 & $0.54 \pm 0.23$ & $0.53 \pm 0.24$ & 0.82 \\
\hline
\end{tabular}

Table 2: Demographic characteristics and biological assessment in patients with acute coronary syndrome in the phase III study.

\begin{tabular}{|c|c|c|c|}
\hline \multirow{2}{*}{$\mathbf{n}$} & ENOXAMED ${ }^{\otimes}$ & LOVENOX ${ }^{\circledR}$ & \multirow{2}{*}{$\mathbf{p}$} \\
\hline & 120 & 118 & \\
\hline \multicolumn{4}{|c|}{ Demographic characteristics } \\
\hline Age (year); mean \pm SD & $60.3 \pm 11.4$ & $61.4 \pm 11.07$ & 0.45 \\
\hline Sex ratio $(M / F)$ & $74 / 46$ & $66 / 52$ & 0.46 \\
\hline Body mass index $\left(\mathrm{kg} / \mathrm{m}^{2}\right)$; mean $\pm \mathrm{SD}$ & $29.1 \pm 4.4$ & $28.5 \pm 3.9$ & 0.34 \\
\hline History of cardiovascular disease $\mathrm{n}(\%)$ & $46(38.3)$ & $49(35.2)$ & 0.69 \\
\hline Diabetes milletus $\mathrm{n}(\%)$ & $63(52.5)$ & $61(51.7)$ & 0.89 \\
\hline Heart failure $\mathrm{n}(\%)$ & $6(5)$ & $12(10.2)$ & 0.47 \\
\hline \multicolumn{4}{|c|}{ Biological assessment } \\
\hline Anti-Xa activity $(\mathrm{IU} / \mathrm{mL}), \mathrm{H} 0$ & $0.01 \pm 0.01$ & $0.008 \pm 0.02$ & 0.41 \\
\hline Anti-Xa activity $(\mathrm{IU} / \mathrm{mL}), \mathrm{H} 4$ & $0.56 \pm 0.13$ & $0.55 \pm 0.12$ & 0.71 \\
\hline
\end{tabular}

Table 3: Demographic characteristics and biological assessment in patients with acute coronary syndrome in the phase IV study.

\section{Discussion}

Biological pharmaceutical products are obtained from extraction from biological tissues or from biotechnological processes and differ from conventional small-molecule medications [1]. The complex structure and activity of LMWHs make the production of a copy more challenging than that of a generic homogenous small molecule drug [10]. Generally, the market authorization requires sufficient data to assure the same level of quality, safety and efficacy of the originator. The extent and the nature of the studies required to obtain a MAA for LMWH copies is an issue of debate [3]. Moreover, enoxaparin has consistently shown its superiority in terms of efficacy when compared to UFH and other LMWHs in the specific clinical setting of antithrombotic management of ACS [12-15].

This study was carried out to compare the anticoagulant potency of a generic enoxaparin (Enoxamed ${ }^{\circ}$ ) with the originator. The bioequivalence was highlighted using first an experimental study performed in healthy volunteers and secondarily validated parameters in ACS patients. The in vitro anti-Xa activities were not significantly different between Enoxamed and the originator. In addition, the effects of the both products on thrombin generation parameters were similar. In this connection, the introduction of a functional criterion in the procedure of the evaluation of the sameness of the copies and the originator product is of value. The CAT was already proposed as a suitable additional tool for this target $[1,10]$. Our clinical studies showed that administration of equal doses of Enoxamed and the originator in patients with ACS results to similar levels of plasma anti$\mathrm{Xa}$ activity measured $4 \mathrm{~h}$ after administration. In addition, there is no significant difference in the occurrence of adverse events between the two compared products.
Generally, it is estimated that almost $80 \%$ of medical prescriptions are filled using generic products. With this increasing use of generic drugs, significant saving could be expected in public health cost. Nevertheless, there are still questions as to whether all generic drugs are in fact identical to their respective reference products $[7,8]$. The FDA approved the first copy of enoxaparin in 2010, using the expedited Abbreviated New Drug Application procedure proposed for requests for marketing authorization of small-molecule chemical drugs [3]. Several copies of enoxaparin are currently available worldwide and appeared in several countries such as China, India and Brazil [3-5]. Enoxamed is the second copy of enoxaparin approved in Tunisia [16].

Available studies showed that generic products of enoxaparin had variable effects on anti-Xa activity since they manifested similar, lower or higher anticoagulant potency than the originator $[1,10]$. This fact raises some concern about the clinical efficacy of these drugs in patients with life threatening conditions as ACS $[8,15]$. Moreover, some authors suggest that it is not safe to treat patients with bio similar copies of enoxaparin on the basis of simplified criteria that are not specific enough to differentiate between different available enoxaparin as anti$\mathrm{Xa}$ activities. In fact, anticoagulation of enoxaparin cannot be explained only in terms of anti-Xa and anti-IIa activities $[3,7,8,10]$. The multiple effects of enoxaparin includes facilitation of the release of tissue factor pathway inhibitor, inactivation of coagulation factors, and activation of platelets, all of which impact the amplitude and the kinetic of thrombin generation inhibition and clot formation [10]. Most published studies did not compare branded and copies of LMWHs on the basis of their global effect on blood coagulation process. As a consequence, they are inconclusive regarding the global functional antithrombotic similarity and sameness of enoxaparin copies compared with the branded product $[1,3]$. Several authors supported this approach and suggested additional global assays of blood coagulation, fibrin formation, and fibrinolysis [10]. Evidence is growing that the parameters of thrombin generation inhibition are useful in assessing bleeding or thrombotic risk and its modification by antithrombotic treatment [9]. The TGT, which was used in our experimental study, offers the opportunity to have a better comparability approach between LMWHs. Our study is one of the first to show that there no differences in the inhibition of thrombin generation between branded enoxaparin and the generic product. Our finding combining anti-Xa activity and thrombin generation parameters would support the possibility to translate this biological efficacy to the clinical setting. Indeed, our data show that clinical outcome was not significantly different between branded enoxaparin and Enoxamed ${ }^{\circ}$.

\section{Conclusion}

In conclusion, the generic enoxaparin Enoxamed ${ }^{\circ}$ showed comparability and then the main regulatory criteria of bioequivalence with the originator product, as demonstrated in our study on the basis of a non-clinical in vitro trial conducted in healthy volunteers and clinical trials (phases III and IV) conducted in patients with ACS.

\section{Conflict of Interest}

This work was supported by Unimed Laboratory, Tunisia. None of the authors received a personal grant to participate in the study.

\section{References}

1. Walenga JM, Jeske WP, Hoppensteadt D, Cunanan J, Khan H, et al. (2013) Comparative studies on branded enoxaparin and a US generic version of enoxaparin. Clin Appl Thromb Hemost 19: 261-267.

2. Hirsh J, Anand SS, Halperin JL, Fuster V (2001) Mechanism of action and pharmacology of unfractionated heparin. Arterioscler Thromb Vasc Biol 21 1094-1096. 
Citation: Sassi M, Beltaief K, Haouala H, Kraiem S, Kammoun S, et al. (2016) Comparability of "Enoxamed" a Tunisian Generic Enoxaparin with the Originator Product: Non-clinical and Clinical Studies. J Bioequiv Availab 8: 249-253. doi: 10.4172/jbb.1000304

3. Harenberg J, Cimminiello C, Agnelli G, Di Minno G, Polo Friz H, et al. (2016) Biosimilars of low-molecular-weight heparin products: fostering competition or reducing 'biodiversity'? J Thromb Haemost 14: 421-426.

4. Feng L, Shen-Tu J, Liu J, Chen J, Wu L, et al. (2009) Bioequivalence of generic and branded subcutaneous enoxaparin: a single-dose, randomized-sequence, open-label, two-period crossover study in healthy Chinese male subjects. Clin Ther 31: 1559-1567.

5. Sharma V, Madhu S, Natarajan P, Muniyandi G, Jaiswal V, et al. (2010) A comparison of the biological activity of 2 formulations of enoxaparin in 12 healthy volunteers. Clin Appl Thromb Hemost 16: 387-393.

6. Drouet L (2012) Low molecular weight heparin biosimilars: how much similarity for how much clinical benefit? Target Oncol 7: S35-S42.

7. Harenberg J (2011) Overview on guidelines and recommendations for generic low-molecular-weight heparins. Thromb Res 127: S100-S104.

8. Jeske W, Walenga JM, Hoppensteadt D, Fareed J (2013) Update on the safety and bioequivalence of biosimilars - focus on enoxaparin. Drug Healthc Patient Saf 5: 133-141.

9. Hemker HC, Al Dieri R, De Smedt E, Béguin S (2006) Thrombin generation, a function test of the haemostatic-thrombotic system. Thromb Haemost 96: 553-561.
10. Gerotziafas GT, Rousseau A, Mbemba E, Khartechi A, Van Dreden P, et al. (2015). Characterization of the antithrombotic fringerprint of the branded and copies of low-molecular-weight enoxaparin using thrombin generation assay. Clin Appl Thromb Hemost 21: 697-704.

11. Hemker HC, Wielders S, Kessels H, Béguin S (1993) Continuous registration of thrombin generation in plasma, its use for the determination of the thrombin potential. Thromb Haemost 70: 617-624.

12. Lee S, Gibson CM (2007) Enoxaparin in acute coronary syndromes. Expert Rev Cardiovasc Ther 5: 387-399.

13. Carter NJ, McCormack PL, Plosker GL (2008) Enoxaparin: A review of its use in ST-segment elevation myocardial infarction. Drugs 68: 691-710.

14. Harrington RA, Becker RC, Cannon CP, Gutterman D, Lincoff AM, et al. (2008) Antithrombotic therapy for non-ST-segment elevation acute coronary syndromes: American College of Chest Physicians Evidence-Based Clinical Practice Guidelines (8th edn.) Chest 133: 670S-707S.

15. Nicolau JC, Cohen M, Montalescot G (2009) Differences among low-molecularweight heparins: evidence in patients with acute coronary syndromes. J Cardiovasc Pharmacol 53: 440-445.

16. Boubaker H, Grissa MH, Sassi M, Chakroun T, Beltaief K, et al. (2015) Generic and Branded Enoxaparin Bioequivalence: A Clinical and Experimental Study. J Bioequiv Availab 7: 225-228. 